\title{
Pediatric Nuclear Medicine Examinations Realized In Senegal from 2009 to 2017: General Characteristics and Diagnostic Contribution
}

\author{
Adambounou $\mathrm{K}^{1,2^{*}}$, Bathily EAL ${ }^{2}$, Djigo $\mathbf{S}^{1}$, Mbodj $\mathbf{M}^{2}$, Ndoye $\mathrm{O}^{2}$, Tapsoba $\mathrm{TL}^{3}$ and Seck-Gassama $\mathbf{S}^{2}$ \\ ${ }^{1}$ Medical Imaging Service, University Hospital Lome, Lome, Togo, West Africa \\ ${ }^{2}$ Nuclear Medicine Service, General Hospital of Grand Yoff (GHGY), Dakar, Senegal, West Africa \\ ${ }^{3}$ Nuclear Medicine Department, University Hospital Yalgado Ouedraogo, Ouagadougou, Burkina Faso
}

*Corresponding author: Adambounou Kokou, Medical Imaging Service, University Hospital Lome, Lome, Togo, West Africa, Tel: 0022890191633; E-mail: kadambounou@yahoo.fr

Received date: October 30, 2017; Accepted date: November 01, 2017; Published date: November 07, 2017

Copyright: (c) 2017 Adambounou K, et al. This is an open-access article distributed under the terms of the Creative Commons Attribution License, which permits unrestricted use, distribution, and reproduction in any medium, provided the original author and source are credited.

\begin{abstract}
Objective: To analyze the profile and the diagnostic contribution of pediatric nuclear medicine examinations realized in Senegal.

Materials and Methods: Retrospective study having included all the files of scintigraphy examinations realized from June 15th, 2009 to June 14th, 2017 for children from 0 to 15 years old in the service of nuclear medicine of the General Hospital Grand Yoff in Dakar.

Results: The examinations had concerned 43 children or $3.6 \%$ of the patients explored in the service. They were mainly male $(65.1 \%)$ and their middle age was of 8.1 years with extremes of 2 months and 15 years. Near $3 / 4$ applicants were pediatricians or a surgeons-pediatrician. Scintigraphies were renal $(67.4 \%)$, thyroid $(18.6 \%)$ and bones $(14 \%)$. Clinical indications were dominated by hydronephrosis $(38.3 \%)$ for renal scintigraphy, goiters $(50 \%)$ for thyroidal scintigraphy and non-traumatic hip pathologies $(66.7 \%)$ for bone scan. Renal scintigraphies had found 9 cases of renal failure of which a bilateral one. The functions of renal filtration separated were symmetric in $31 \%$ and asymmetric in $37.9 \%$. The renal drainage was altered for $37.9 \%$ of right kidney and $58.6 \%$ of left kidney with an ascendancy of the functional retentions. The arguments suggestive of Basedow disease were found in $50 \%$ case for the thyroid scintigraphies, of femoral osteonecrosis and osteo-articular infection in $33.3 \%$ each for bones scans.
\end{abstract}

Conclusion: Nuclear pediatrics examinations although weakly realized has a decisive diagnostic contribution in the pediatric care in Senegal.

Keywords: Scintigraphy; Children; Pediatric medical imaging; Senegal; Developing countries

\section{Introduction}

Pediatric nuclear medicine or nuclear pediatrics regroups all the isotopic explorations performed in children. Isotopic exploration in adults as well as in children are led by scintigraphic imaging that plays an important role by other medical imaging methods side (radiodiagnosis, echography, magnetic resonance imaging) in the medical care of several pathologies. In the years 1960 to 1970, the application to children of scintigraphic imaging techniques was extremely restraint, because of long half-life radiopharmaceuticals, that could lead to a high level of irradiation and then unusable in children $[1,2]$.

The progressive development of new radiopharmaceuticals, particularly the preferential use of short physical half-life (6 hours) Technetium-99m $\left.{ }^{99 \mathrm{~m}} \mathrm{Tc}\right)$, associated to the improvement of detection and analysis techniques, has given an advancement to pediatric radioisotopic imaging [2]. The indications of pediatric scintigraphic imaging have then been widen to all the systems of human body and nuclear pediatrics is nowadays considered as a whole specialty of nuclear medicine specially in western countries [3].
Unfortunately, the scarcity of nuclear medicine services in our developing countries has made nuclear pediatrics very little developed and rare are the scientific studies consecrated to the place of scintigraphic examinations in the medical pediatric care in Africa [4]. We have then undertaken this study which general objective is to analyze the profile and the diagnostic contribution of pediatric scintigraphic examinations realized in Senegal since the creation of the nuclear medicine department in the General Hospital Grand Yoff (GHGY) of Dakar in June 2009 till 2017.

\section{Method and Materials}

It was a retrospective study that has included all the records of scintigraphic examinations realized from June 15th, 2009 to June 14th, 2017 (or 8 years) in children from 0 to 15 years in the nuclear medicine department of GHGY of Dakar. This department, which is the only nuclear medicine service of Senegal, is functional since June 2009 and have at its disposal a double head gamma-camera type MEDISO NUCLINE TM SPIRIT DH-V with a wide range, provided with a low energy and high resolution parallel collimator. The isotopic in vitro explorations realized in children were not included in this work.

The general characteristics (age, sex, height, weight, town of origin, examination type, prescribers' qualification) of the examinations and 
Citation: Adambounou K, Bathily EAL, Djigo S, Mbodj M, Ndoye O, et al. (2017) Pediatric Nuclear Medicine Examinations Realized In Senegal from 2009 to 2017: General Characteristics and Diagnostic Contribution. J Nucl Med Radiat Ther 8: 344. doi: $10.4172 / 2155-9619.1000344$

Page 2 of 7

their diagnostic contribution (indications, biological and imaging assessment, scintigraphic diagnosis after interpretation) have been analyzed. Data have been analyzed and treated with the statistic software Sphinx ${ }^{\circledR}$ 5.3.1.

The qualitative data have been treated with Microsoft Word ${ }^{\bullet} 2013$ and graphics have been made with Microsoft Excel ${ }^{\circledR} 2013$. The results have been tested by Khi 2 test. A difference inferior to 0.05 has been considered significant. Some results have been submitted to Pearson correlation coefficient with a correlation judged positively strong if $r$ is comprised between 0.5 and 1 .

\section{Results}

\section{General characteristics of the scintigraphic examinations realized}

During our survey period, the pediatric scintigraphic examinations has been realized on 43 children over a total of 1186 patients explored in the service representing $3.6 \%$ of all the scintigraphic imaging acts realized in Senegal during this period. More than a half of the children have been explored during the last 3 years of our study (Figure 1).

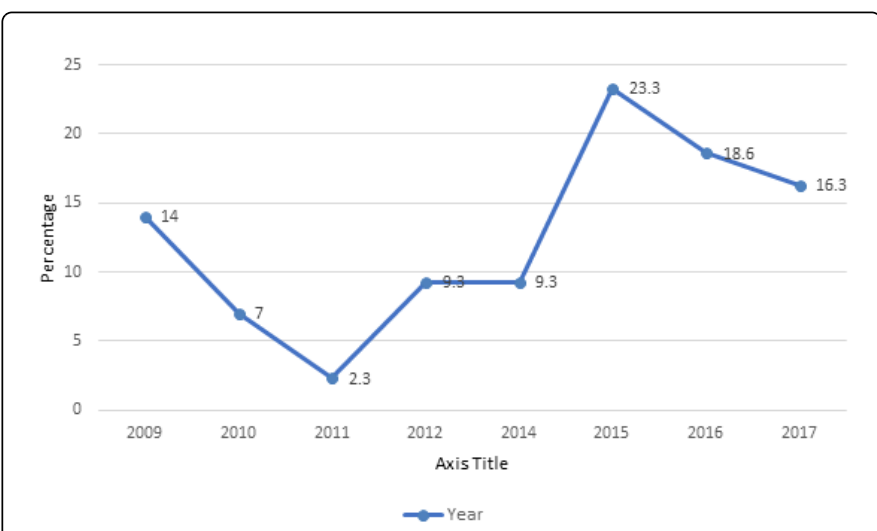

Figure 1: Evolution of the frequency of the scintigraphic examinations according to their year of realization.

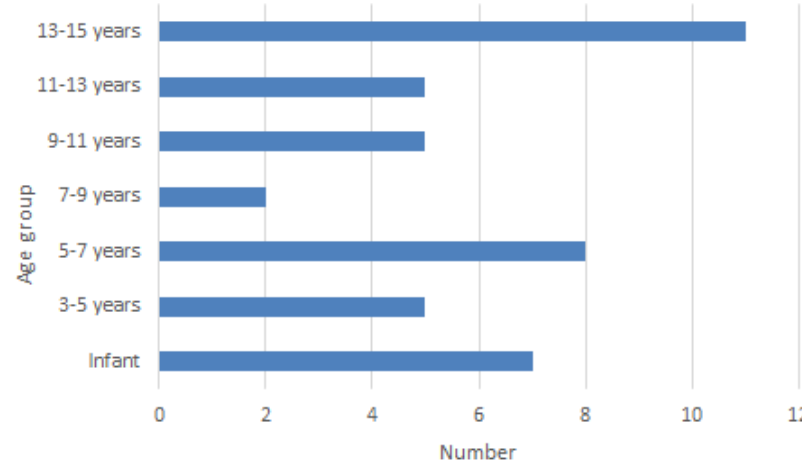

Figure 2: Distribution of the scintigraphic examinations according to the age of the children.
Those children were divided in 28 boys $(65.1 \%)$ and 15 girls (34.9\%). The middle age was 8.1 years with extremes of 2 months and 15 years. The range of 13-15 years was the most represented followed respectively by 5-7 years children and infants (Figure 2). The middle weight was $27.7 \mathrm{~kg}$ and the middle height $134 \mathrm{~cm}$. The great majority of children (34) or $79.1 \%$ came from the town of Dakar; 7 children or $16.3 \%$ came from the other towns of Senegal and 2 (4.7\%) from neighboring countries. They were 41 children (95.3\%) referred by a public health facility and 2 or $4.7 \%$ by a private one. About $3 / 4$ of the prescribers were children's doctors (pediatricians and pediatric surgeons) and only $2.3 \%$ were general practitioners (Figure 3 ).

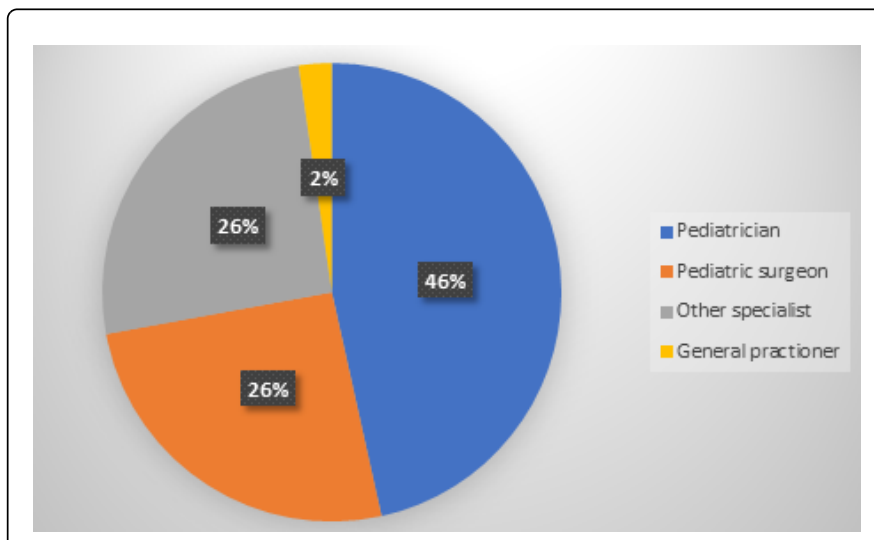

Figure 3: Distribution of the scintigraphic examinations according to the qualification of the applicants.

\section{Realization techniques, clinical indications and diagnostic contribution of scintigraphic exams}

Scintigraphic examinations realized were of 3 types knowing renal ( 29 cases or $67.4 \%$ ), thyroidal ( 8 cases or $18.6 \%$ ) and bone (6 cases or $14 \%)$. Thyroidal scintigraphies were realized only in older children and were the only to have a female predominance (Table 1).

Radiopharmaceuticals used were the ${ }^{99 \mathrm{~m} T c-H M D P}$ for bone scintigraphy in all the cases, ${ }^{99} \mathrm{~m} T c$ for thyroidal scintigraphy, the ${ }^{99 \mathrm{~m}}$ Tc-DTPA for renal scintigraphy, the ${ }^{99 \mathrm{~m}} \mathrm{Tc}-\mathrm{DMSA}$ for static exploration has been used for 3 patients that have already benefit of a first dynamic renal ${ }^{99 \mathrm{~m}} \mathrm{Tc}-\mathrm{DTPA}$ scintigraphy.

Table 2 shows the middle, minimal and maximal activity in MBq of radiotracers injected by type of exam according to the age of children. The middle activity injected was strongly correlated with the age of children ( $\mathrm{p}=0.001 ; \mathrm{r}=0.77)$.

All the acquisitions of the different scintigraphic images were planar conventional. The clinical indications were various and led by hydronephrosis ( $1 / 3$ of the cases) for renal scintigraphy; goiters $(50 \%)$ for thyroidal scintigraphy and non-traumatic hip pathology in a lameness context ( $2 / 3$ cases) for bone scintigraphy (Table 3$)$.

The results of the biological explorations were available in 16 scintigraphic records $(37.2 \%)$ and for the other medical imaging examinations in 23 records (53.5\%). Table 4 shows the results of the various medical imaging examinations realized before the scintigraphic exploration. 
Citation: Adambounou K, Bathily EAL, Djigo S, Mbodj M, Ndoye O, et al. (2017) Pediatric Nuclear Medicine Examinations Realized In Senegal from 2009 to 2017: General Characteristics and Diagnostic Contribution. J Nucl Med Radiat Ther 8: 344. doi: $10.4172 / 2155-9619.1000344$

Page 3 of 7

\begin{tabular}{|c|c|c|c|c|c|c|}
\hline \multirow{2}{*}{ Variables } & \multicolumn{2}{|l|}{ Renal } & \multicolumn{2}{|l|}{ Bone } & \multicolumn{2}{|l|}{ Thyroidal } \\
\hline & Number & Percentage (\%) & Number & Percentage (\%) & Number & Percentage (\%) \\
\hline \multicolumn{7}{|l|}{ Age group } \\
\hline Infant & 7 & 24.1 & 0 & 0 & 0 & 0 \\
\hline $3-5$ years & 4 & 13.8 & 1 & 16.7 & 0 & 0 \\
\hline 5-7 years & 7 & 24.1 & 1 & 16.7 & 0 & 0 \\
\hline $7-9$ years & 2 & 6.9 & 0 & 0 & 0 & 0 \\
\hline 9-11 years & 4 & 13.8 & 0 & 0 & 1 & 12.5 \\
\hline $11-13$ years & 1 & 3.4 & 1 & 16.7 & 3 & 37.5 \\
\hline $13-15$ years & 4 & 13.8 & 3 & 50 & 4 & 50 \\
\hline \multicolumn{7}{|l|}{ Sex } \\
\hline Male & 22 & 75.9 & 5 & 83.3 & 1 & 12.5 \\
\hline Female & 7 & 24.1 & 1 & 16.7 & 7 & 87.5 \\
\hline
\end{tabular}

Table 1: Distribution of 3 types of scintigraphic examinations realized according to the age and the sex of the children.

\begin{tabular}{|c|c|c|c|c|c|c|c|c|c|}
\hline \multirow{2}{*}{ Variables } & \multicolumn{3}{|l|}{ Renal } & \multicolumn{3}{|l|}{ Bone } & \multicolumn{3}{|c|}{ Thyroidal } \\
\hline & Middle & Min & $\operatorname{Max}$ & Middle & Min & $\operatorname{Max}$ & Middle & Min & Max \\
\hline 0 & 32.5 & 32 & 33 & - & - & - & - & - & - \\
\hline 1 & 37.8 & 30 & 47 & - & - & - & - & - & - \\
\hline 2 & 44 & 44 & 44 & - & - & - & - & - & - \\
\hline 3 & 60.5 & 54 & 67 & - & - & - & - & - & - \\
\hline 4 & 55.5 & 54 & 57 & 356 & 356 & 356 & - & - & - \\
\hline 5 & 44.2 & 37 & 56 & - & - & - & - & - & - \\
\hline 6 & 69.5 & 56 & 83 & 258 & 258 & 258 & - & - & - \\
\hline 7 & 37 & 37 & 37 & - & - & - & - & - & - \\
\hline 8 & 74 & 74 & 74 & - & - & - & - & - & - \\
\hline 9 & 72.3 & 59 & 95 & - & - & - & - & - & - \\
\hline 10 & 44 & 44 & 44 & - & - & - & 107 & 107 & 107 \\
\hline 11 & - & - & - & 371 & 371 & 371 & 111 & 111 & 111 \\
\hline 12 & - & - & - & - & - & - & 141 & 141 & 141 \\
\hline 13 & - & - & - & - & - & - & 74 & 74 & 74 \\
\hline 14 & 142 & 142 & 142 & 522 & 522 & 522 & - & - & - \\
\hline 15 & 133 & 59 & 174 & 608 & 604 & 612 & 115 & 81 & 148 \\
\hline Total & 63.1 & 30 & 174 & 454 & 258 & 612 & 111 & 74 & 148 \\
\hline
\end{tabular}

Table 2: Distribution of the middle, minimal and maximal activity in $\mathrm{MBq}$ of the radiotracers injected by type of scintigraphic examination according to the age (years) of the children. 
Citation: Adambounou K, Bathily EAL, Djigo S, Mbodj M, Ndoye O, et al. (2017) Pediatric Nuclear Medicine Examinations Realized In Senegal from 2009 to 2017: General Characteristics and Diagnostic Contribution. J Nucl Med Radiat Ther 8: 344. doi: $10.4172 / 2155-9619.1000344$

Page 4 of 7

\begin{tabular}{|c|c|c|}
\hline Variables & Number & Percentage (\%) \\
\hline \multicolumn{3}{|l|}{ Renal scintigraphy } \\
\hline Acalculous hydronephrosis & 11 & 32.4 \\
\hline Calculous hydronephrosis & 2 & 5.9 \\
\hline Uretero-hydonephrosis & 4 & 11.8 \\
\hline Renal ectopy & 3 & 8.8 \\
\hline Multicystic dysplasia & 3 & 8.8 \\
\hline Renal tumor & 2 & 5.9 \\
\hline Mega-ureter & 2 & 5.9 \\
\hline Renal failure & 2 & 5.9 \\
\hline Vesico-renal reflux & 1 & 2.9 \\
\hline Renal malrotation & 1 & 2,9 \\
\hline Renal atrophy & 1 & 2.9 \\
\hline Renal traumatism & 1 & 2.9 \\
\hline Global assessment & 1 & 2.9 \\
\hline \multicolumn{3}{|l|}{ Thyroidal scintigraphy } \\
\hline Goiter with hyperthyroidism & 4 & 50 \\
\hline Thyroidal nodule & 2 & 25 \\
\hline Cervical tumefaction & 2 & 25 \\
\hline \multicolumn{3}{|l|}{ Bone scintigraphy } \\
\hline Non-traumatic hip pathology & 4 & 66.6 \\
\hline Knee osteosarcoma extension assessment & 1 & 16.7 \\
\hline Tuberculous spondylodiscitis & 1 & 16.7 \\
\hline
\end{tabular}

Table 3: Distribution of the frequency of the indications of every type of scintigraphic examination.

The great majority of the scintigraphic examinations realized were revealed pathologic of which all thyroidal scintigraphies (Table 5).

Table 6 shows that there was no statistically significant relation of the scintigraphic diagnosis results neither with the demographic data of children nor with the qualifications and the health facilities of practice of the prescribers.

\begin{tabular}{|l|l|l|l|l|l|l|}
\hline \multirow{2}{*}{ Variables } & Normal & Pathologic & \multicolumn{2}{l|}{ Total } \\
\cline { 2 - 8 } & Number & Percentage (\%) & Number & Percentage (\%) & Number & Percentage (\%) \\
\hline Radiography & 0 & 0 & 2 & 6.3 & 2 & 5.9 \\
\hline Tomodensitometry & 0 & 0 & 14 & 43.7 & 14 & 41.2 \\
\hline Echography & 2 & 100 & 16 & 50 & 18 & 52.9 \\
\hline Total & 2 & 100 & 32 & 100 & 34 & 100 \\
\hline
\end{tabular}

Table 4: Results of the diverse medical imaging examinations realized before the scintigraphic exploration. 
Citation: Adambounou K, Bathily EAL, Djigo S, Mbodj M, Ndoye O, et al. (2017) Pediatric Nuclear Medicine Examinations Realized In Senegal from 2009 to 2017: General Characteristics and Diagnostic Contribution. J Nucl Med Radiat Ther 8: 344. doi: $10.4172 / 2155-9619.1000344$

Page 5 of 7

\begin{tabular}{|l|l|l|l|l|}
\hline \multirow{2}{*}{ Variables } & \multicolumn{2}{|l|}{ Normal } & Pathologic \\
\cline { 2 - 5 } & Number & Percentage (\%) & Number & Percentage (\%) \\
\hline Renal $(n=29)$ & 2 & 6.9 & 27 & 93.1 \\
\hline Bone $(n=6)$ & 1 & 16.7 & 5 & 83.3 \\
\hline Thyroidal $(n=8)$ & 0 & 0.0 & 8 & 100 \\
\hline Total $(n=43)$ & 3 & 7.0 & 40 & 93.0 \\
\hline
\end{tabular}

Table 5: Distribution of the scintigraphic diagnostic results according to the type of examination.

\begin{tabular}{|c|c|c|c|c|c|}
\hline \multirow[b]{2}{*}{ Variables } & \multicolumn{2}{|l|}{ Normal } & \multicolumn{2}{|c|}{ Pathologic } & \multirow[t]{2}{*}{$P$ value } \\
\hline & Number & Percentage (\%) & Number & Percentage (\%) & \\
\hline \multicolumn{5}{|l|}{ Age } & 0.753 \\
\hline Infant & 0 & 0 & 7 & 17.5 & \\
\hline $3-5$ years & 0 & 0 & 5 & 12.5 & \\
\hline $5-7$ years & 0 & 0 & 8 & 20 & \\
\hline $7-9$ years & 1 & 33.3 & 1 & 2.5 & \\
\hline $9-11$ years & 0 & 0 & 5 & 12.5 & \\
\hline $11-13$ years & 1 & 33.3 & 4 & 10 & \\
\hline $13-15$ years & 1 & 33.3 & 10 & 25 & \\
\hline \multicolumn{5}{|l|}{ Sex } & 0.624 \\
\hline Male & 3 & 100 & 25 & 62.5 & \\
\hline Female & 0 & 0 & 15 & 37.5 & \\
\hline \multicolumn{5}{|l|}{ City of origin } & 0.653 \\
\hline Dakar & 3 & 100 & 31 & 77.5 & \\
\hline Other Senegal town & 0 & 0 & 7 & 17.5 & \\
\hline Other Africa town & 0 & 0 & 2 & 5 & \\
\hline \multicolumn{5}{|c|}{ Prescriber qualification } & 0.273 \\
\hline Pediatrician & 3 & 100 & 17 & 42.5 & \\
\hline Pediatric surgeon & 0 & 0 & 11 & 27.5 & \\
\hline Other specialist & 0 & 0 & 11 & 27.5 & \\
\hline General practioner & 0 & 0 & 1 & 2.5 & \\
\hline
\end{tabular}

Table 6: Diagnostic results of the scintigraphic examinations according to the age, the sex, the city of origin of the children and the qualification of the applicants.

The renal scintigraphic explorations have retrieved 8 cases of renal unilateral muteness of which 5 concerning the right kidney and one case of bilateral renal muteness. The separated renal filtration functions were symmetric in 9 cases (31\%) and asymmetric in 11 cases (37.9\%).

The renal drainage (elimination) was altered for $37.9 \%$ of right kidney and $58.6 \%$ of left kidney and we noticed a predominance of functional renal retentions (inorganic) right as well as left (Table 7).
The scintigraphic thyroidal interpretation has found evocative signs of Basedow disease in 4 cases (50\%), warm nodule, cold nodule and blank scintigraphy respectively in one case each.

The scintigraphic signs evocative of aseptic osteonecrosis of femur head in 2 cases $(33,3 \%)$, osteoarticular infection in 2 cases $(33.3 \%)$, bone metastasis in 1 case were found during the bone scintigraphies interpretation. 
Citation: Adambounou K, Bathily EAL, Djigo S, Mbodj M, Ndoye O, et al. (2017) Pediatric Nuclear Medicine Examinations Realized In Senegal from 2009 to 2017: General Characteristics and Diagnostic Contribution. J Nucl Med Radiat Ther 8: 344. doi: $10.4172 / 2155-9619.1000344$

Page 6 of 7

\begin{tabular}{|l|l|l|l|l|}
\hline \multirow{2}{*}{ Variables } & \multicolumn{2}{l|}{ Right kidney } & \multicolumn{2}{l|}{ Left kidney } \\
\cline { 2 - 5 } & Number & $\begin{array}{l}\text { Percentage } \\
(\%)\end{array}$ & Number & $\begin{array}{l}\text { Percentage } \\
(\%)\end{array}$ \\
\hline Normal & 12 & 41.4 & 8 & 27.6 \\
\hline Functional retention & 7 & 24.1 & 13 & 44.8 \\
\hline Organic retention & 4 & 13.8 & 4 & 13.8 \\
\hline Mute kidney & 6 & 20.7 & 4 & 13.8 \\
\hline Total & 29 & 100 & 29 & 100 \\
\hline
\end{tabular}

Table 7: Distribution of the drainage quality of each kidney.

\section{Discussion}

Our work has collected the pediatric scintigraphies examinations realized in the nuclear medicine department of GHGY of Dakar that is the only service of nuclear medicine in Senegal. Our results are then representative of the whole Senegal. The number of children who have benefited of a nuclear medicine examination in 8 years in Senegal is very weak if we compare it to the 1307 acts of pediatric nuclear medicine in vivo realized in 2000 in Geneva, Switzerland [2]. In Chicago in USA, the number of nuclear pediatrics acts was estimated to 1854 acts yet in 1975 [5]. We must notice that the weak number of nuclear pediatrics acts is related to the weak number of the whole number of nuclear medicine acts realized in Senegal which was 1186 acts during the 8 years of our study period when in France, it was estimated to 1.103 .000 acts in 2012 according to the report on French population exposure to medical ionizing radiations in 2012 [6]. The realization frequency of the pediatric nuclear medicine examinations which was of $3.6 \%$ of all the nuclear medicine acts of Senegal is also weak if we compare it to the pediatric tomodensitometries in Togo or Côte d'Ivoire that were about $11 \%$ each $[7,8]$. A distinct male predominance of the children in our study (sex-ratio=1.9) has also been observed in pediatric tomodensitometry imaging in Togo and in Côte d'Ivoire [7,8]. Tapsoba et al. have also reported a global male predominance on the whole scintigraphic examinations realized in 2012 in Burkina-Faso [9]. If no newborn has benefit from a scintigraphic examination in our sample, however it is important to remind that scintigraphic imaging can be realized at all pediatric age even in newborns if the clinical indication is justified. The $4.7 \%$ of children coming from Senegal neighboring countries can probably be explained by the absence of nuclear medicine department in those countries. In fact, African countries are characterized by a penury of nuclear medicine department and numerous are the sub-Saharan African countries that do not have nuclear medicine department [4]. Pediatric nuclear medicine examinations as well as adult ones are generally not first intention examinations and then are often prescribed by children's specialists explaining the great frequency of pediatricians and pediatric surgeons among the applicants of the realized scintigraphies in this study.

Renal scintigraphy with $67.3 \%$ was the most realized in our study, followed by thyroidal scintigraphy (18.6\%). This situation is not the same in France where, according to IRSN data, pediatric scintigraphies were essentially bony (48\%) and urogenital (36\%) [10]. The predominance of renal scintigraphy in nuclear pediatrics is related to the prevalence of urinary infections in children on one hand and to the relatively high frequency of malformation urinary diseases of which scintigraphic imaging plays a determinant role in the therapeutic

orientation on the other hand. Hydronephrosis is one of the frequent manifestation of those urinary congenital diseases in majority obstructive and whose leader is the pyelo-ureteral junction syndrome. It is then not surprising to remark that $1 / 3$ of the indications of renal scintigraphy in Senegal is represented by hydronephrosis.

Beyond uro-genital pathologies, scintigraphic imaging plays also an important role in bone pathologies of children. Thus, in France for example, the number of bone scintigraphy realized in the nuclear pediatrics department of Trousseau Hospital of Paris is stable, about 1000 per year, for ten years, and this, despite the installation of MRI devices [11]. The main indications of those bone scintigraphies in that service concerned essentially bone infection suspicions, suspicions of fracture with normal radiography and extension assessment of bone tumor. Pediatric bone infections such osteomyelitis are frequent in Africa but unfortunately our result show that Senegal clinicians do not turn to profit scintigraphic imaging in its early caring because we have noticed any indication concerning osteomyelitis. The strong prevalence of sickle cell disease in Africa whose one complication is the aseptic osteonecrosis of femur head that is hardly diagnosed in its initial phase by standard radiography, could be the reason why bone scintigraphy indications were dominated by non-traumatic hip pathologies.

Goiters are frequent in Africa and the second place occupied by thyroidal scintigraphy in our study shows that thyroidal dysfunction are common in older children in Senegal. The absence of thyroidal exploration in the infant and small child in our study is surely related to unavailability of iodine 123 . In fact, the thyroidal scintigraphy with $123 \mathrm{I}$ is essential in congenital hypothyroidisms care. It has today an inescapable place in the etiologic diagnosis of congenital hypothyroidism, in association with echography. Ismaili et al. have reported during the period from January, 2005 to December, 2008, 181 cases of thyroidal scintigraphic explorations realized in infant aged of zero to three months in the nuclear medicine department of EnfantsArmand-Trousseau Hospital (France). Among them, 162 have less than a month, 15 have between one and two months [12].

Clinician doctors especially African ones have often the mistaken conception that scintigraphic examinations are very irradiant, more than all the radiology examinations [13]. This is the origin of their weak infatuation toward nuclear medicine especially pediatric. If it is true that the prescription of an irradiant examination to a patient should respect first of all the first principle of radioprotection which is the justification that should be more rigorously respected in children, it is also true that the pediatric scintigraphic examinations are in general less irradiant than most of all the pediatric radiologic examinations [14]. In fact, nuclear pediatrics has widely benefited from the evolutions brought not only to radiopharmaceutical drugs but also to detector systems. Thus iodine 131 used in nuclear pediatrics' beginning has been abandoned for ${ }^{99} \mathrm{~m} \mathrm{Tc}$ less irradiant and easily detectable by cameras [15]. The radiopharmaceuticals used have also the advantage to be administered at a trace estate comparatively to the volumes of contrast products used in radiology. The tolerance for child is then clearly improved. Thus, in the case of altered renal function, a scintigraphy can be prescribed with a great security, what iodized contrast products examinations can not necessarily offer [16,17]. Despite all these evolutions, the nuclear doctor has to choose the most appropriate radiopharmaceuticals for the child and administrate it with an adapted posology in sight of an optimal optimization of the irradiation dose. Thus, for dynamic renal scintigraphy for example, the MAG3 is the most indicated in pediatrics. Unfortunately, this radiopharmaceutical is almost not used in the nuclear medicine 
Citation: Adambounou K, Bathily EAL, Djigo S, Mbodj M, Ndoye O, et al. (2017) Pediatric Nuclear Medicine Examinations Realized In Senegal from 2009 to 2017: General Characteristics and Diagnostic Contribution. J Nucl Med Radiat Ther 8: 344. doi: $10.4172 / 2155-9619.1000344$

Page 7 of 7

department of GHGY probably because of its accessibility problems. Efforts should be then made to prefer the MAG3 to DTPA in nuclear medicine department of GHGY. Our work shows also that if the administration posologies of radiopharmaceuticals were increasing with the patients' age, they were neither made according to a well determined posology rule nor conform to the EANM Paediatric dosage card [18]. Improvements should also be brought in that sight for a maximal optimization of pediatric irradiation doses in the department.

The scintigraphic examinations are generally very sensitive but little specific and it is important to correlate them not only with the clinic but also with the biology for a better diagnostic orientation. The knowledge of the results of biological exploration of the $37.2 \%$ of children in this study should then be very useful for nuclear doctors during their interpretation of scintigraphic images. Scintigraphic imaging is often complementary of the others medical imaging methods. It is generally asked in second intention as it is the case in $53.5 \%$ in our study. The weak proportion of the examinations with a normal report in this study is comforting and shows a justification high enough of scintigraphic examinations requirements as well as their important contribution in the medical care of explored children.

The scintigraphic interpretation has revealed a case of bone metastasis. The capital place of whole body bone scan in the detection of osteophilic cancers metastases especially osteocondensant such as the cancer of prostate, breasts in adults is no more necessary to demonstrate. In children to date, bone scintigraphy is a part of extension assessment of children sarcomas, whether are teenagers osteosarcomas, Ewing sarcoma or rhabdomyosarcomas that are observed since the little childhood. Those indications concern actually a little less than $10 \%$ of the patients in France and it is almost always children whose diagnosis is already known [11]. In our case, it was a bone metastasis of a knee osteosarcoma.

The different scintigraphic renal abnormalities found in our study come to confirm the determinant role of renal scintigraphy in pediatric urinary diseases by bringing precious functional information to the clinician for a better therapeutic orientation.

\section{Conclusion}

The part of nuclear pediatrics is relatively weak in nuclear in vivo medicine services in Dakar. Scintigraphic examinations realized were widely dominated by renal scintigraphy and prescribers were also generally pediatricians and pediatric surgeons. The results of the different scintigraphic examinations realized have showed the determinant diagnostic contribution of nuclear pediatrics in the medical care of children.

\section{References}

1. Rouy JC, Tafani M, Guillet J (2012) Nuclear medicine and pediatrics: Radiopharmaceutical point of view. Med Nucl 36: 124-127.

2. AllaouaD M, Slosman O (2001) Nuclear Medicine and Pediatrics. Rev Med Switzerland 3: 21153.

3. Guillet J (2012) Nuclear pediatrics in Europe. Med Nucl 36: 119-123.

4. Objects FI (2008) Nuclear medicine practice in Africa. West Afr JRadio 15: 22-27.

5. Conway JJ (2006) A memoir of pediatric nuclear medicine: Part III: finding a place for nuclear medicine. J Nucl Med 47: 14N-24N.

6. Exposure of the French population to ionizing radiation related to medical diagnostic acts in 2012. PRP-HOM report $\mathrm{N}^{\circ}$ 2014-6.

7. Adambounou K, Lawson-Evi K, Gnakadja N, Gbande P, Adigo AMY, et al. (2015) Tomodensitometry in the medical care of children in Togo: Profiles and technical conditions of realization. J Rech Sci Univ 17: 251-258.

8. N'goan-Domoua AM, Kouame N, Zod TB (2013) Computed tomography in the management of infantile diseases at Yopougon University Hospital. Review int sci med 15: 20-24.

9. Tapsoba TL, Sanon H, Ouattara TF, Ouedraogo SJ, Gansonre KV (2012) Summary of the first six months of operation of the nuclear medicine department of the university hospital Yalgado Ouedraogo. Med Nucl 36: 514-517.

10. Exposure of children to ionizing radiation linked to diagnostic procedures in 2010 in France. PRP-HOM report N ${ }^{\circ} 2013-3$.

11. Labriolle-Vaylet C, Sergeant-Alaoui A, Chrestian P, Puech B (2012) Pediatric bone scintigraphy, hospital practice in 2011. Med Nucl 36: 140-145.

12. Ismaili AN, Hindie E, Sergent AA, Fakir S, Mouzoune S, et al. (2012) Thyroid scintigraphy in congenital hypothyroidism: About 181 examinations in children under three months of age. Med Nuc 36: 479-485.

13. Adambounou K, Adjut KV, Achy OB, KE Mossi, Gbande P, et al. (2015) Knowledge and Perception of Nuclear Medicine by Togolese Doctors. Nuc Med 39: e15-e20.

14. Treves ST, Falone AE, Fahey FH (2014) Pediatric nuclear medicine and radiation dose. Semin Nucl Med 44: 202-209.

15. Schmit P, Glorion C (2004) Osteomyelitis in infants and children. Eur J Radiol 14: 44-54.

16. Offiah AC (2006) Acute osteomyelitis, septic arthritis and discitis: Differences between neonates and older children. Eur J Radiol 60: 221-232.

17. Milcent K, Guitton C, Koné-Paul I (2009) National survey on the management of osteomyelitis in children. Arch Pediatr 16: 7-13.

18. Lassmann M, Biassoni L, Monsieurs M, Franzius C, Jacobs F (2007) The new EANM paediatric dosage card. Eur J Nucl Med Mol Imaging 34: 796-798. 